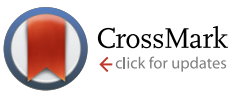

Cite this: React. Chem. Eng., 2016, 1, 101

Received 23rd November 2015, Accepted 23rd December 2015

DOI: $10.1039 / c 5 r e 00082 c$

rsc.li/reaction-engineering

\title{
A multistep continuous flow synthesis machine for the preparation of pyrazoles via a metal-free amine-redox processtt
}

\author{
Jian-Siang Poh, ${ }^{a}$ Duncan L. Browne ${ }^{* a b}$ and Steven V. Ley ${ }^{a}$
}

A versatile multistep continuous flow setup is reported for the four-step conversion of anilines into pyrazole products. The synthesis machine incorporates the use of amine-redox chemistry through diazotization and a metal-free vitamin C mediated reduction. The machine can be used for the synthesis of an array of analogues or the scale up of an individual target.

\section{Introduction}

The synthesis of heterocyclic compounds continues to serve as a cornerstone for the preparation of materials necessary for our modern society. The way in which such materials are constructed is therefore an important area of research whereby ease of diversity, simplicity of scale up and sustainability of the method represent key factors in the future advancement of this established field. In the case of pyrazoles, five-membered heterocycles featuring two adjacent nitrogen atoms, their functionality is characterized by their appearance in materials, agrochemicals and pharmaceuticals, examples of which are celecoxib (1), crizotinib, sildenafil and pyrazoxyfen (Fig. 1a). ${ }^{1}$ At scale these compounds are most commonly prepared by the cyclo-condensation of hydrazines with 1,3-dicarbonyl compounds or their equivalents. This can be achieved by either the cyclo-condensation with simple hydrazine followed by a non-selective alkylation of a tautomeric mixture, or by appropriate substitution of hydrazine followed by an electronically controlled regioselective cyclocondensation (Fig. 1b). The latter approach is often preferred as it leads to more selective processes. However, both strategies require the preparation and storage of hydrazines on scale, a practice which represents a significant safety risk, economic investment and is applicable to a relatively limited substrate scope.

Substituted hydrazines are often prepared by nucleophilic aromatic substitution $\left(\mathrm{S}_{\mathrm{N}} \mathrm{Ar}\right)$ of the appropriately activated

\footnotetext{
${ }^{a}$ Department of Chemistry, University of Cambridge, Lensfield Road, Cambridge, CB2 $1 E W, U K$

${ }^{b}$ School of Chemistry, Cardiff University, Main Building, Park Place, CF10 3AT, UK. E-mail: dlbrowne@cardiff.ac.uk

$\dagger$ Raw spectra can be found at https://www.repository.cam.ac.uk/handle/1810/ 252343.

\$ Electronic supplementary information (ESI) available. See DOI: 10.1039/ c5re00082c
}

benzene systems, or more recently, utilising palladiumcatalysed cross-coupling methods with hydrazine. In the latter case, the scope has been increased by the development of important ligands that permit a difficult reductive elimination step. ${ }^{2}$ Although this cross-coupling approach may have some way to go before its application on scale becomes economically and environmentally sustainable, some headway has been made with the development of a continuous flow approach. ${ }^{3}$ An alternative option, which permits access to a vast range of substituted hydrazines centres on the use of amine-redox chemistry. This method consists of oxidation through diazotization, followed by reduction of the $\mathrm{N}-\mathrm{N}$ triple bond, commonly with tin(II) chloride (Fig. 1b). ${ }^{4}$

However, in recent years there has been an interest in moving towards more sustainable reductants, those that can be washed away from the product through simple aqueous extraction where ascorbic acid or sodium sulfite serve as reductant, including our own previous mechanistic work and flow proof-of-concept. ${ }^{5}$ Here we describe the first report of an end-to-end multistep ${ }^{6}$ continuous flow process $^{7}$ for the amine-redox cycle followed by hydrolysis of the hydrazine surrogate and ensuing cyclo-condensation, a process characterised by low inventories of both diazonium salt and hydrazine at any one time and the use of vitamin $\mathrm{C}$ as reductant. $^{8}$

\section{Results and discussion}

Our first experiments towards this goal commenced with the development of compatible flow conditions for the reduction stage followed by hydrolysis and cyclo-condensation (Fig. 2). Aiming for $N$-arylated pyrazoles, we tested the performance of the setup by injecting 0.8 mmol segments of 4-trifluoromethylbenzenediazonium tetrafluoroborate (2, 0.2 $\mathrm{M}$ in $\mathrm{MeCN}$ ) and $\mathrm{L}_{\text {-ascorbic }}$ acid (3, 0.2 $\mathrm{M}$ in $\mathrm{H}_{2} \mathrm{O}$ ) which were 


\section{a}

a pharmaceuticals/agrochemicals containing the pyrazole motif<smiles>Cc1ccc(-c2cc(C(F)(F)F)nn2-c2ccc(S(N)(=O)=O)cc2)cc1</smiles><smiles>CCCc1nn(C)c2c(=O)[nH]c(-c3cc(S(=O)(=O)N4CCN(C)CC4)ccc3OCC)nc12</smiles>

b

analysis of pyrazole-forming reactions

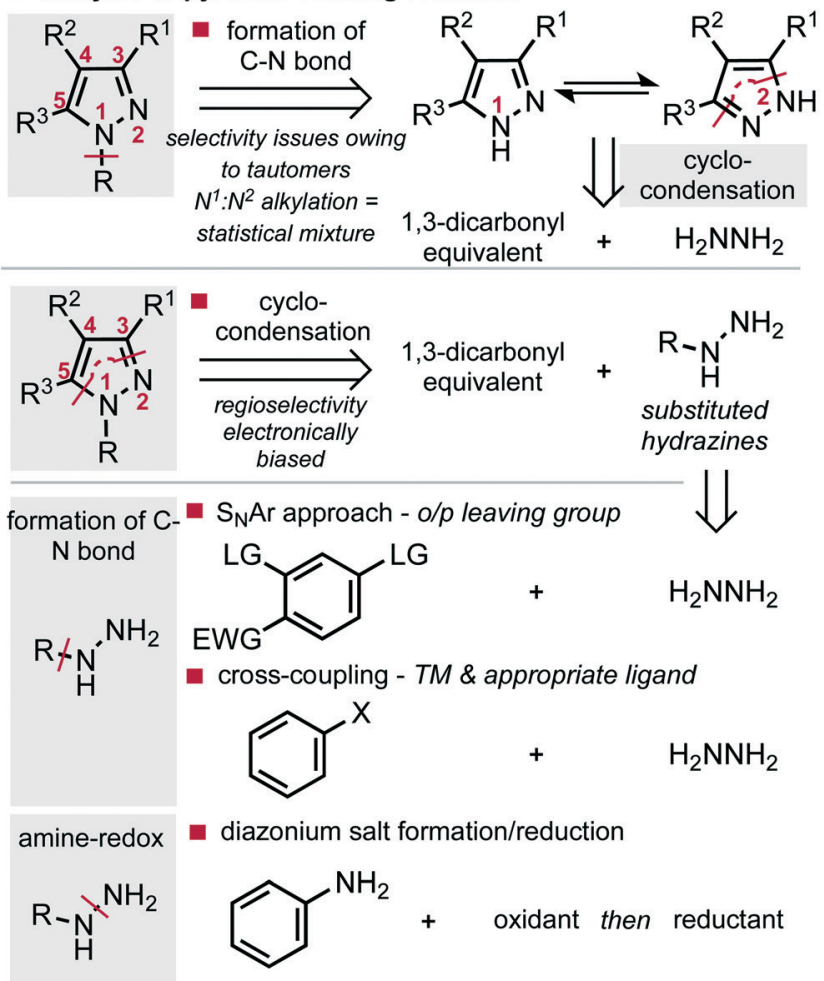

Fig. 1 a Examples of pyrazole scaffolds. b Synthetic approaches towards pyrazole scaffolds.

combined at a T-piece and passed through a preliminary reactor coil where the reduction stage could take place. This solution then passed through an in-line flow IR device which served two purposes: (i) to monitor the presence of the desired carbonyl stretching frequency resulting from the oxamate moiety as well as to monitor levels of diazonium compound still on-stream; (ii) to actively control the flow rate of a third pump ${ }^{9}$ delivering both pentane-2,4-dione and the hydrochloric acid necessary for oxamate cleavage so that stoichiometries could be matched with the flowing segment, thus delivering matched concentration profiles.

Once combined with the acid and the dione, the stream then passed through a heated coil before emerging at the output through a 100 psi back-pressure regulator. The flow procedure developed here offers advantages over batch procedures, allowing rapid screening of reaction conditions with minimal operator input, as well as the in situ formation of unstable and/or explosive intermediates (hydrazides and hydrazines) to minimize operator exposure.

With an appropriate apparatus setup to optimize the three-step reduction/hydrolysis/cyclo-condensation sequence established, various parameters were investigated (Table 1). Notably, it was found that the final yield of pyrazole was highly dependent on the residence time for the reduction step with $t_{\mathrm{R}}=6 \mathrm{~min}$ appearing to be optimal; a decreased residence time does not allow the reduction to proceed to completion, whereas increased residence times result in greater decomposition of hydrazide 4 . We are mindful here of recent reports on the catalytic generation of radical intermediates through the action of ascorbic acid on diazonium salts as a likely competing pathway. ${ }^{10}$ There is also an optimum temperature for reactor coil 2 around $140{ }^{\circ} \mathrm{C}$, where higher than this seemed to result in reduced yields of pyrazole products. Optimal conditions were found (Table 1, entry 4), providing pyrazole 5 in $69 \%$ yield after isolation.

Next we sought to assess the scope of the reaction, but with the following modifications to the flow procedure: (i) it would be preferable for the diazonium salts to also be produced in situ from their corresponding anilines, thus avoiding the isolation and handling of additional explosive species; (ii) a transformation of the procedure from segmented flow to continuous flow would allow safe scale-up to provide gram-quantities of $\mathrm{N}$-arylated pyrazoles. A 'diazotization module' was easily incorporated into the existing flow set-up to replace the diazonium tetrafluoroborate input stream, resulting in a four-step telescoped flow procedure (Fig. 3a).

In order to assess whether the new flow set-up with the in situ generation of diazonium chloride salts (as opposed to the tetrafluoroborate salts) was compatible with the existing reduction, hydrolysis and condensation steps, we subjected 4-trifluoromethylaniline to the fully telescoped process, undergoing diazotization with 1 equiv. of $t$-butyl nitrite, reduction with 1 equiv. of L-ascorbic acid and condensation with 1.1 equiv. of pentane-2,4-dione, run under continuous flow conditions for $2 \mathrm{~h}$. Pleasingly, the desired pyrazole 5 was isolated in $69 \%$ yield over four steps, in good agreement with the previously optimized results. Scope of the reaction and flow process with respect to anilines was then explored. In general, most electron-withdrawing substituents on the anilines were tolerated (Fig. 3b). Notably, anthranilic acid, whose diazonium derivative is known to decompose (explosively, if uncontrolled) to benzyne could be effectively employed in the flow process and provided pyrazole 7 in $61 \%$ yield. 


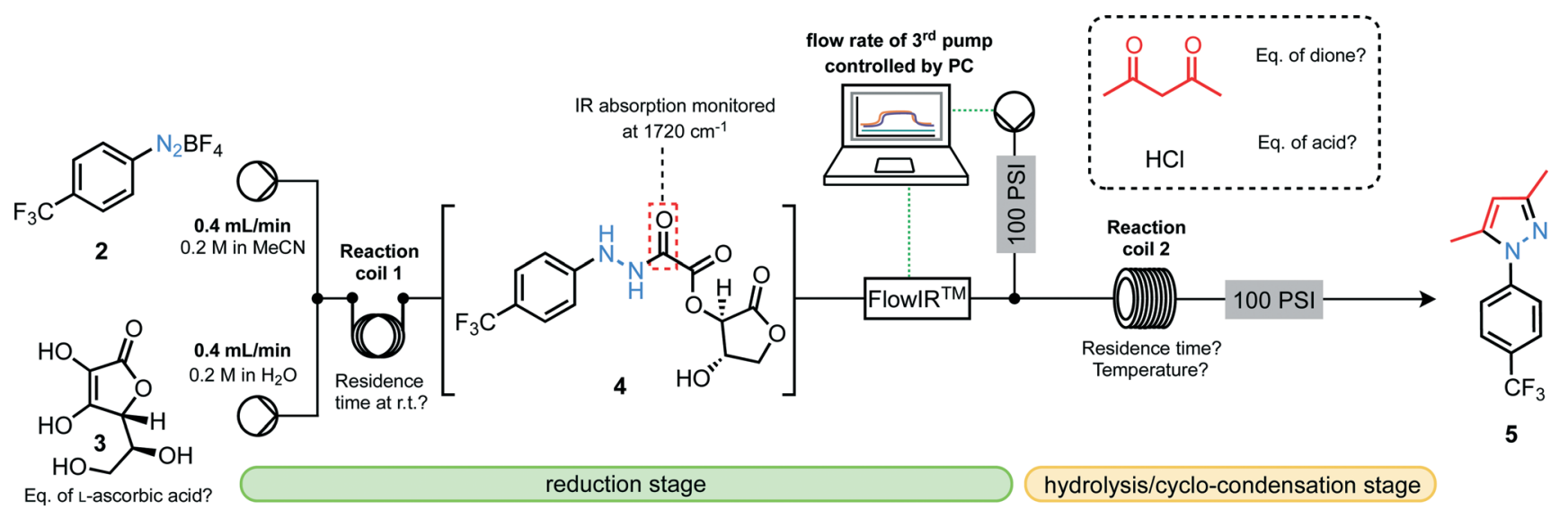

Fig. 2 Equipment setup for segmented flow reduction/hydrolysis/cyclo-condensation sequence.

Table 1 Optimization of conditions for segmented flow reduction/hydrolysis/cyclo-condensation sequence

\begin{tabular}{lllll}
\hline Entry & Coil $1, t_{\mathrm{R}} / \mathrm{min}$ & Coil $2, T /{ }^{\circ} \mathrm{C}$ & Equiv. of HCl & Yield $^{a}(\%)$ \\
\hline 1 & 2.5 & 100 & 5.5 & 21 \\
2 & 2.5 & 140 & 5.5 & 46 \\
$3^{b}$ & 2.5 & 140 & 5.5 & 45 \\
4 & 6 & 140 & 5.5 & $71(69)$ \\
5 & 10 & 140 & 5.5 & 67 \\
6 & 18 & 140 & 5.5 & 62 \\
7 & 35 & 140 & 5.5 & 58 \\
8 & 6 & 100 & 5.5 & 21 \\
9 & 6 & 120 & 5.5 & 55 \\
10 & 6 & 160 & 5.5 & 53 \\
$11^{c}$ & 6 & 140 & 5.5 & 70 \\
$12^{d}$ & 6 & 140 & 5.5 & 71 \\
13 & 6 & 140 & 0 & 35 \\
14 & 6 & 140 & 2.2 & 68 \\
15 & 6 & 140 & 11 & 58
\end{tabular}

All entries run on $0.8 \mathrm{mmol}$ scale with respect to diazonium tetrafluoroborate, with r.t. in coil 1 and a 35 minute residence time in reactor coil 2, 1.1 equivalents of dione and 1 equivalent of ascorbic acid. ${ }^{a}$ Yield determined from quantitative ${ }^{1} \mathrm{H}$ NMR analysis with DMF as internal standard, yield of isolated product in parentheses. ${ }^{b} 63$ minute residence time in reactor coil $2 .{ }^{c} 2.2$ equivalents of dione used. ${ }^{d} 2$ equivalents of ascorbic acid used.

Conversion of the 4-pentafluorosulfanyl amine to pyrazole 12 via its corresponding, previously unknown, hydrazine proceeded in a moderate $45 \%$ yield. Electron-rich systems such as 4-methoxyaniline were not tolerated in the reduction step, but heteroaromatic ring systems were applicable; both 3-amino-2-chloropyridine and 3-aminoquinoline provided the desired pyrazoles (11 and 13) in good yields.

Next, a variety of 1,3-dicarbonyl compounds or equivalents were examined in the telescoped multistep process (Fig. 3c). The unsymmetrical 1,3,4-tricarbonyl compound 14 provided pyrazoles 15 (ref. 11) and 16 as single regioisomers, in a combined yield of $78 \%$. Acetylenic ketone 17 and 3-aminocrotononitrile (19) were also converted to pyrazole 18 and 20 (ref. 11) respectively as single regioisomers within the standard operating conditions of this pyrazole synthesising machine. Enaminone 21 was also an effective substrate leading to $57 \%$ yield of a $3: 1$ mixture of pyrazole regioisomers (22a and 22b).

As a further illustration of the utility of the telescoped procedure, perhaps as a machine to aid possible drug discovery, a selection of relevant 1,3-diketones were crossed with aniline starting materials to yield pyrazole analogues of celecoxib (1) as a product output (Fig. 3d). Furan-bearing, pentafluorosulfanyl pyrazole 23 was furnished in $46 \%$ yield, whereas the $N$-pyridyl variant (24) was isolated in $48 \%$ yield. A scale-up experiment where the machine was running for a 12 hour period demonstrated the synthesis of the 4-nitrophenyl analogue 25 in 40\% yield, affording $3.76 \mathrm{~g}$ of the isolated pyrazole product. Finally, the appropriate sulfanilamide was diazotized, reduced with L-ascorbic acid, hydrolyzed and condensed with the corresponding dione to provide the COX-2 selective non-steroidal anti-inflammatory drug celecoxib (1) in $48 \%$ yield over four continuous steps.

\section{Conclusions}

In summary, we have reported a metal-free continuous flow method for the generation of a variety of $\mathrm{N}$-arylated pyrazoles via amine-redox chemistry. The telescoped flow process offers a distinct advantage over corresponding batch procedures due to the in situ formation and use of several reactive intermediates. Critically, this end-to-end style of synthesis avoids the stock-piling and storage of hazardous drug intermediates (diazonium salts and hydrazines) by advancing them to the next step as they are produced. The machine, and conditions/parameters reported here are applicable to a relatively broad range of amine and 1,3-dicarbonyl materials. Further investigations into the handling and use of reactive intermediates in flow as well as the development of multistep machines to support the synthesis and discovery process are currently ongoing in our laboratories. 
a) equipment setup for the four-stage multistep amine-redox/hydrolysis/cyclo-condensation continuous flow process

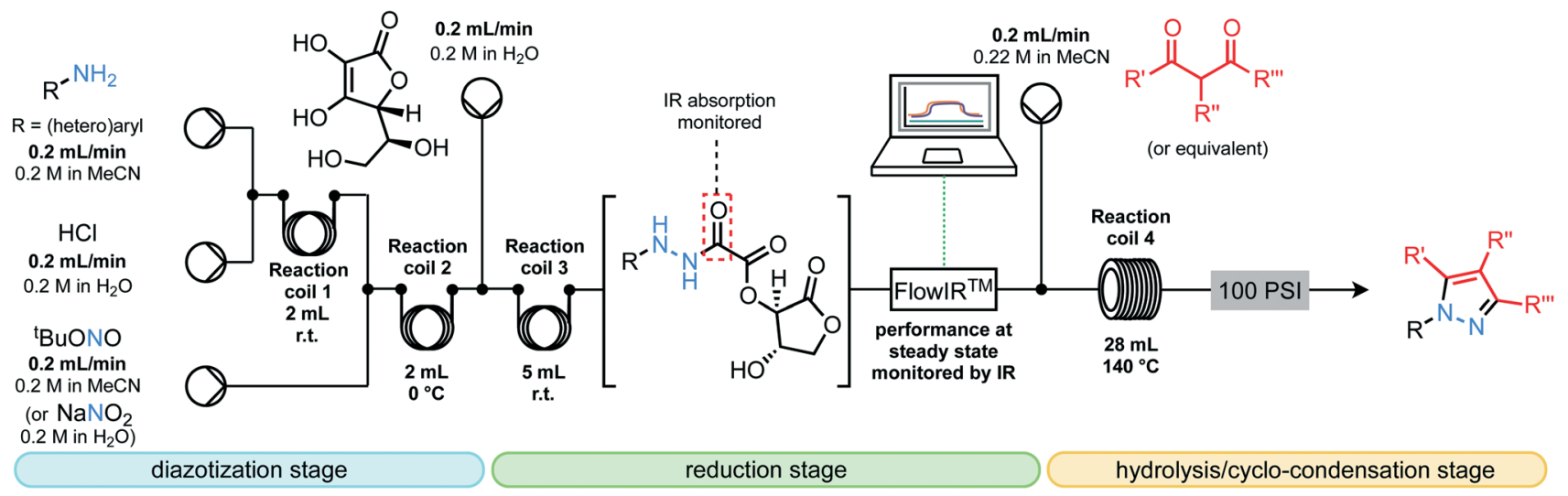

b) scope with respect to (hetero)aryl aniline component $[$ a]<smiles>Cc1cc(C)n(-c2ccc([N+](=O)[O-])cc2)n1</smiles>

6. $76 \%$<smiles>Cc1cc(C)n(-c2ccc(F)cc2)n1</smiles>

$10,55 \%$<smiles>Cc1cc(C)n(-c2ccccc2C(=O)O)n1</smiles>

$7,61 \%[b]$<smiles>Cc1cc(C)n(-c2cccnc2Cl)n1</smiles>

$11,51 \%[b]$<smiles>Cc1cc(C)n(-c2cccc(Br)c2)n1</smiles>

8, $69 \%$<smiles>Cc1cc(C)n(-c2ccc(F)cc2)n1</smiles>

$12,45 \%$<smiles>Cc1cc(C)n(-c2ccc(CCO)cc2)n1</smiles>

$9,57 \%[b, c]$<smiles>Cc1cc(C)n(-c2cnc3ccccc3c2)n1</smiles>

$13,56 \%[b]$

a) scope with respect to 1,3 dicarbonyl equivalent $[\mathrm{a}]$

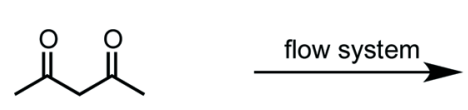<smiles>CCCC1CCN1c1ccc(C(F)(F)F)cc1</smiles>

$5,69 \%$<smiles>CC(=O)C#Cc1ccccc1</smiles><smiles>CNC=CC(=O)c1cccs1</smiles>

21
$18,57 \%$<smiles>Cc1cc(-c2ccccc2)n(-c2ccc(C(F)(F)F)cc2)n1</smiles>

flow system

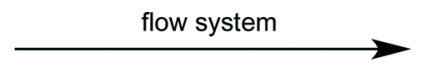

$\mathrm{F}_{3} \mathrm{C}$<smiles>CCOC(=O)CC(=O)C1CC1</smiles>

14

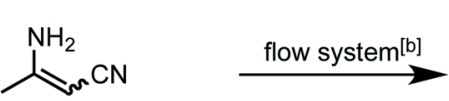

19<smiles>FC(F)(F)c1ccc(-n2nccc2-c2cccs2)cc1</smiles>

22a

$57 \%, 72: 28,22 a: 22 b$<smiles>[R]C#[R16][AsH2]</smiles>

- d) pyrazole 'pick ' $n$ ' mix' and scaled runs ${ }^{[a]}$<smiles>Fc1ccc(-n2nc(C(F)(F)F)cc2-c2ccco2)cc1</smiles>

$23,46 \%$<smiles>FC(F)(F)c1cc(-c2ccccc2)n(-c2cccnc2Cl)n1</smiles>

$24,48 \%$<smiles>O=[N+]([O-])c1ccc(-n2nc(C(F)(F)F)cc2-c2ccco2)cc1</smiles>

$25,40 \%\left[{ }^{[d]}, 3.76 \mathrm{~g}\right.$<smiles>Cc1cc(N)n(-c2ccc(C(F)(F)F)cc2)n1</smiles>

$20,64 \%$<smiles>FC(F)(F)c1ccc(-n2ccc(-c3cccs3)n2)cc1</smiles>

Fig. 3 Equipment setup and scope for the continuous flow diazotization/reduction/hydrolysis/cyclo-condensation sequence. ${ }^{a}$ Entries run on 4.8 mmol scale with respect to aniline unless otherwise stated, yields represent isolated product. ${ }^{b}$ Using $\mathrm{NaNO}_{2}$ in $\mathrm{H}_{2} \mathrm{O}$ as diazotizing agent. ${ }^{c}$ Using a $15 \mathrm{~mL}$ reaction coil at $30{ }^{\circ} \mathrm{C}$ for the reduction module. ${ }^{\mathrm{d}}$ Run on $28.8 \mathrm{mmol}$ scale over 12 hours. 


\section{Acknowledgements}

We thank Prof. Tony Kirby for insightful discussions regarding the reaction mechanism. We are also grateful to the Cambridge Home and European Scholarship Scheme (JSP) and EPSRC (DLB and SVL, grant numbers EP/K0099494/1 and EP/ K039520/1) for financial support.

\section{Notes and references}

1 (a) S. Fustero, M. Sánchez-Roselló, P. Barrio and A. SimónFuentes, Chem. Rev., 2011, 111, 6984; (b) Y. L. Janin, Chem. Rev., 2012, 112, 3924; (c) T. Eicher, S. Hauptmann and A. Speicher, The Chemistry of Heterocycles: Structures, Reactions, Synthesis, and Applications, Wiley-VCH, 3rd edn, 2012; (d) J. A. Joule and K. Mills, Heterocyclic Chemistry, WileyBlackwell, 5th edn, 2010, For examples of continuous flow approaches towards pyrazoles see: $(e)$ I. R. Baxendale, S. C. Schou, J. Sedelmeier and S. V. Ley, Chem. - Eur. J., 2010, 16, 89; $(f)$ C. J. Smith, F. J. Iglesias-Sigüenza, I. R. Baxendale and S. V. Ley, Org. Biomol. Chem., 2007, 5, 2758; $(g) \mathrm{H}$. Lange, C. F. Carter, M. D. Hopkin, A. Burke, J. G. Goode, I. R. Baxendale and S. V. Ley, Chem. Sci., 2011, 2, 765; (h) D. Obermayer, T. N. Glasnov and C. O. Kappe, J. Org. Chem., 2011, 76, 6657; (i) J. R. Breen, G. Sandford, D. S. Yufit, J. A. K. Howard, J. Fray and B. Patel, Beilstein J. Org. Chem., 2011, 7, 1048; ( $j$ ) M. Damm, T. N. Glasnov and C. O. Kappe, Org. Process Res. Dev., 2010, 14, 215; (k) C. Battilocchio, B. J. Deadman, N. Nikbin, M. O. Kitching, I. R. Baxendale and S. V. Ley, Chem. - Eur. J., 2013, 19, 7917.

2 R. J. Lundgren and M. Stradiotto, Angew. Chem., Int. Ed., 2010, 49, 8686.

3 A. DeAngelis, D.-H. Wang and S. L. Buchwald, Angew. Chem., Int. Ed., 2013, 52, 3434.

4 For a continuous flow process using tin(II) chloride as a reducing agent for diazonium salts, see: $(a) \mathrm{B}$. Li, D. Widlicka, S. Boucher, C. Hayward, J. Lucas, J. C. Murray, B. T. O'Neil, D. Pfisterer, L. Samp, J. VanAlsten, Y. Xiang and J. Young, Org. Process Res. Dev., 2012, 16, 2031, For the use of tin(II) chloride as a reducing agent for diazonium salts in patent literature, see: (b) R. Baker, V. G. Matassa and L. J. Street, Merck Sharp and Dohme Ltd., US Pat., 5298520, 29 March 1994.

5 For methods utilising sodium sulfite, see: (a) G. H. Coleman, Org. Synth., 1922, 2, 71; (b) J. P. Koilpillai, M. Subramanian, U. Mallela, V. B. Boddu, R. Dandala and S. Meenakshisunderam, Aurobindo Pharma Ltd., WO Pat., 2008/075163, 26 June 2008; (c) Z. Yu, G. Tong, X. Xie, P. Zhou, Y. Lv and W. Su, Org. Process Res. Dev., 2015, 19, 892, For methods utilising L-ascorbic acid, see: (d) M. Marinozzi, G. Marcelli, A. Carotti and B. Natalini, RSC Adv., 2014, 4, 7019; (e) C. P. Ashcroft, P. Hellier, A. Pettman and S. Watkinson, Org. Process Res. Dev., 2011, 15, 98; $(f)$ T. Norris, C. Bezze, S. Z. Franz and M. Stivanello, Org. Process Res. Dev., 2009, 13, 354; (g) D. L. Browne, I. R. Baxendale and S. V. Ley, Tetrahedron, 2011, 67, 10296.
6 For recent reviews on flow chemistry, see: (a) J. C. Pastre, D. L. Browne and S. V. Ley, Chem. Soc. Rev., 2013, 42, 8849; (b) S. V. Ley, D. E. Fitzpatrick, R. Ingham and R. M. Myers, Angew. Chem., Int. Ed., 2015, 54, 3449; (c) S. V. Ley, D. E. Fitzpatrick, R. Myers, C. Battilocchio and R. J. Ingham, Angew. Chem., Int. Ed., 2015, 54, 10122; (d) B. Gutmann, D. Cantillo and C. O. Kappe, Angew. Chem., Int. Ed., 2015, 54, 6688; (e) K. F. Jensen, B. J. Reizman and S. G. Newman, $L a b$ Chip, 2014, 14, 3206; $(f)$ N. G. Anderson, Org. Process Res. Dev., 2012, 16, 852; $(g)$ I. R. Baxendale, J. Chem. Technol. Biotechnol., 2013, 88, 519.

7 For examples of some recent multistep flow processes, see: (a) J. Hartwig, S. Ceylan, L. Kupracz, L. Coutable and A. Kirschning, Angew. Chem., Int. Ed., 2013, 52, 9813; (b) D. Ghislieri, K. Gilmore and P. H. Seeberger, Angew. Chem., Int. Ed., 2015, 54, 678; (c) S. Newton, C. F. Carter, C. M. Pearson, L. de C. Alves, H. Lange, P. Thansandote and S. V. Ley, Angew. Chem., Int. Ed., 2014, 53, 4915; (d) L. Kupracz and A. Kirschning, Adv. Synth. Catal., 2013, 355, 3375; (e) J. C. Pastre, D. L. Browne, M. O'Brien and S. V. Ley, Org. Process Res. Dev., 2013, 17, 1183; $(f)$ P. R. D. Murray, D. L. Browne, J. C. Pastre, C. Butters, D. Guthrie and S. V. Ley, Org. Process Res. Dev., 2013, 17, 1192; (g) C. Battilocchio, I. R. Baxendale, M. Biava, M. O. Kitching and S. V. Ley, Org. Process Res. Dev., 2012, 16, 798; (h) M. A. Kabeshov, B. Musio, P. R. D. Murray, D. L. Browne and S. V. Ley, Org. Lett., 2014, 16, 4618; (i) S.-H. Lau, A. Galván, R. R. Merchant, C. Battilocchio, J. A. Souto, M. B. Berry and S. V. Ley, Org. Lett., 2015, 17, 3218; $(j)$ M. Chen and S. L. Buchwald, Angew. Chem., Int. Ed., 2013, 52, 4247; (k) C. A. Correia, K. Gilmore, D. T. McQuade and P. H. Seeberger, Angew. Chem., Int. Ed., 2015, 54, 4945; ( $l$ ) T. Tsubogo, H. Oyamada and S. Kobayashi, Nature, 2015, 520, 329.

8 For some recent examples of controlling hazardous chemistry in flow see: (a) S. T. R. Müller, D. Smith, P. Hellier and T. Wirth, Synlett, 2014, 25, 871; (b) J. A. Newby, D. W. Blaylock, P. M. Witt, J. C. Pastre, M. K. Zacharova, S. V. Ley and D. L. Browne, Org. Process Res. Dev., 2014, 18, 1211; (c) J. A. Newby, D. W. Blaylock, P. M. Witt, R. M. Turner, P. L. Heider, B. H. Harji, D. L. Browne and S. V. Ley, Org. Process Res. Dev., 2014, 18, 1221; (d) B. Gutmann, P. Elsner, A. O'Kearney-McMullan, W. Goundry, D. M. Roberge and C. O. Kappe, Org. Process Res. Dev., 2015, 19, 1062; (e) A. A. Kulkarni, Beilstein J. Org. Chem., 2014, 10, 405; $(f)$ J.-I. Yoshida, Y. Takahashi and A. Nagaki, Chem. Commun., 2013, 49, 9896.

9 H. Lange, C. F. Carter, M. D. Hopkin, A. Burke, J. G. Goode, I. R. Baxendale and S. V. Ley, Chem. Sci., 2011, 2, 765.

10 (a) B. Majhi, D. Kundu and B. C. Ranu, J. Org. Chem., 2015, 80, 7739; (b) F. P. Crisóstomo, T. Martín and R. Carrillo, Angew. Chem., Int. Ed., 2014, 53, 2181.

11 CCDC 1430558 and 1430559 contain the supplementary crystallographic data for this paper. These data are provided free of charge by The Cambridge Crystallographic Data Centre. 